\title{
Sentinel node identification in clinical stage la non-small cell lung cancer by a combined single photon emission computed tomography/computed tomography system
}

Hiroaki Nomori, MD, PhD, ${ }^{a}$ Koei Ikeda, MD, PhD, ${ }^{a}$ Takeshi Mori, MD, PhD, ${ }^{a}$ Shinya Shiraishi, MD, PhD, ${ }^{b}$ Hironori Kobayashi, MD, ${ }^{a}$ Kazunori Iwatani, MD, ${ }^{a}$ Koichi Kawanaka, MD, PhD, ${ }^{\mathrm{b}}$ and Toshiaki Kobayashi, MD, $\mathrm{PhD}^{\mathrm{c}}$

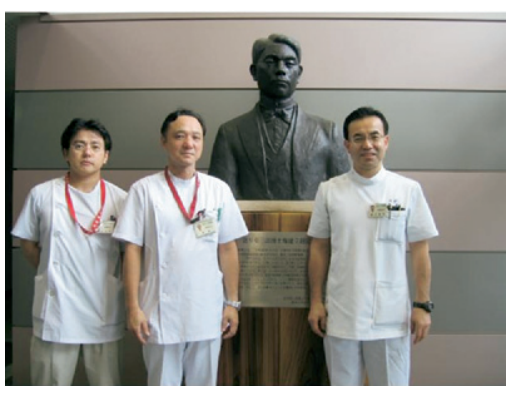

Drs Nomori, Mori, and Ikeda (left to right). The bronze statue is Dr. Shibasaburo Kitasato.

Objective: A gamma probe can identify sentinel nodes before nodal dissection in the mediastinum but not in the hilum, owing to high radioactivity from primary tumors. We evaluated the utility of fused single photon emission computed tomography/ computed tomography (SPECT/CT) images for the identification of sentinel nodes in the hilum for patients with clinical stage Ia non-small cell lung cancer.

Methods: Technetium- $99 \mathrm{~m}$ tin colloid was injected into the peritumoral region approximately 18 hours before surgery in 63 patients with clinical stage Ia nonsmall cell lung cancer. On the morning of the operation, approximately 16 hours after administration of tin colloid, sentinel nodes were identified by fused SPECT/ CT; this was followed by intraoperative sentinel node identification in the dissected lymph nodes by gamma probe. Because the gamma probe is a standard method for sentinel node identification, the sensitivity of fused SPECT/CT images was examined on the basis of the data of the gamma probe.

Results: Fused SPECT/CT images could identify sentinel nodes at segmental and lobar lymph nodes with a sensitivity of 0.87 and 0.74 , both of which were significantly higher than 0.40 in the mediastinum $(P<.001$ and $P=.012$, respectively). In 5 patients with pathologic N1 or N2 disease, both SPECT/CT and the gamma probe could identify sentinel nodes with metastases.

Conclusions: SPECT/CT could identify sentinel nodes of the hilum especially in segmental and lobar lymph nodes but not in the mediastinum. Because the gamma probe can identify sentinel nodes before nodal dissection in the mediastinum but not in the hilum, a combination of SPECT/CT and the gamma probe can be used to identify sentinel nodes before nodal dissection in both the hilum and the mediasti-

From the Departments of Thoracic Surgery $^{\mathrm{a}}$ and Radiology, ${ }^{\mathrm{b}}$ Graduate School of Medical Sciences, Kumamoto University, Honjo, Kumamoto, and the ${ }^{\mathrm{c}}$ Department of Assistive Diagnostic Technology, National Cancer Center Hospital, Tsukiji, Chuo-ku, Tokyo, Japan.

Received for publication Dec 3, 2006; revisions received Jan 21, 2007; accepted for publication Feb 7, 2007.

Address for reprints: Hiroaki Nomori, MD, $\mathrm{PhD}$, Department of Thoracic Surgery, Graduate School of Medical Sciences, Kumamoto University, 1-1-1 Honjo, Kumamoto 860-8556, Japan (E-mail: hnomori@ qk9.so-net.ne.jp).

J Thorac Cardiovasc Surg 2007;134:182-7

$0022-5223 / \$ 32.00$

Copyright (๑) 2007 by The American Association for Thoracic Surgery

doi:10.1016/j.jtcvs.2007.02.013 num, which will enable sentinel node navigation surgery in non-small cell lung cancer.

$\mathrm{S}$ entinel lymph node (SN) sampling with a gamma probe has allowed surgeons to be more selective in performing a formal lymph node dissection in melanoma, breast cancer, and gastrointestinal cancers. ${ }^{1-3}$ However, the gamma probe method in lung cancer surgery cannot identify SNs before lymph node dissection in the hilum owing to high radioactivity from primary tumors. ${ }^{4,5}$ Therefore, previously reported SN identifications with the gamma probe method in lung cancer surgery have been based on radioactivity measured in the dissected lymph nodes,${ }^{5-10}$ which cannot be used to guide lymph node dissection or sampling. This difficulty with the gamma probe method makes it difficult for SN navigation surgery to be of practical use in non-small cell lung cancer (NSCLC).

Planar scintigram with a radioactive colloid has also been used to identify SNs, especially in melanoma of the head and neck. ${ }^{11-13}$ However, in lung cancer surgery, localization of nodal stations by planar scintigram is difficult because SNs cannot 


$$
\begin{aligned}
& \text { Abbreviations and Acronyms } \\
& \text { CT }=\text { computed tomography } \\
& \text { NSCLC }=\text { non-small cell lung cancer } \\
& \text { SN }=\text { sentinel lymph node } \\
& \text { SPECT }=\text { single photon emission computed tomography } \\
& { }_{99 \mathrm{~m}}^{\mathrm{T} c}=\text { technetium-99m }
\end{aligned}
$$

readily be discriminated owing to the lack of tomography images. In 2002, we installed a combined single photon emission computed tomography/computed tomography (SPECT/ CT) system that is composed of a gantry-free gamma camera and an 8-row multidetector CT. So that we can avoid positional differences between the SPECT and CT studies, imaging is performed on the same platform, which makes fusion of SPECT and high-performance CT images possible. Because the SPECT/CT system has enabled us to identify SNs on the basis of the fusion images, without the adverse effect of overlapping radioactivity from the primary site, it allows preoperative SN localization in relation to nearby anatomic structures, which enables an intraoperative $\mathrm{SN}$ biopsy to be easy and accurate. $\mathrm{We}^{14}$ previously identified SNs in 35 patients with melanoma by the SPECT/CT system; the identification rate was $100 \% .^{14}$ The present study evaluated the usefulness of fused SPECT/CT images, compared with the gamma probe, for $\mathrm{SN}$ identification in lung cancer surgery.

\section{Patients and Methods \\ Patient Eligibility}

This study of SN identification in patients with clinical stage Ia NSCLC was approved by the ethical committee of the Graduate School of Medical Sciences, Kumamoto University, in March 2005. Clinical staging was performed by body CT, brain magnetic resonance imaging, and positron emission tomography. Informed consent was obtained from all patients after a discussion with the surgeons regarding the risks and benefits. Eligible patients had clinical stage Ia peripheral type NSCLC and were candidates for lobectomy or segmentectomy with mediastinal lymph node dissection. The patients without preoperative histologic diagnosis of tumors were excluded. The lobectomy with mediastinal lymph node dissection was performed via thoracoscopy, as described before. ${ }^{15}$ Segmentectomy with hilar and mediastinal lymph node dissection was performed via open thoracotomy, as described before. ${ }^{16}$ All of the lymph nodes at the hilum were dissected during segmentectomy with taping of the vessels and bronchus.

\section{Lymph Node Nomenclature}

The lymph node nomenclature used was based on the original lymph node map for lung cancer. ${ }^{17}$

\section{Administration of Radioactive Colloid}

Administration of the radioactive colloid was based on the method reported previously. ${ }^{4,5}$ In the SPECT/CT room, approximately 18 hours before the operation, 6 to $8 \mathrm{mCi}$ of technetium- $99 \mathrm{~m}\left({ }^{99 \mathrm{~m}} \mathrm{Tc}\right)$ tin colloid suspended in a volume of 1 to $1.5 \mathrm{~mL}$ was injected into the peritumoral region.

\section{SPECT/CT System}

On the morning of the operation, approximately 16 hours after administration of the ${ }^{99 \mathrm{~m}} \mathrm{Tc}$ tin colloid, SNs were identified by the SPECT/CT system. This system was composed of a commercially available gantry-free SPECT with dual-head detectors (Skylight; ADAC Laboratories, Milpitas, Calif) and an 8 multidetector-row CT scanner (Light-Speed Ultra Instrument; General Electric, Milwaukee, Wis). The two instruments were juxtaposed so that the CT table bearing the patient could be moved directly into the SPECT scanner before CT scanning. As a result, each patient was identically positioned for SPECT and CT imaging.

SPECT data acquisition was performed with a vertex generalpurpose parallel-hole (VXGP) collimator. A 360 SPECT scan was acquired and was followed by CT scanning. Reconstructive CT images were processed into Digital Imaging and Communications in Medicine (DICOM) data and then transferred to Pegasys (ADAC Laboratories, Milpitas, Calif), which is a workstation for SPECT processing. One lumen of a 3-way stopcock (inner diameter $4 \mathrm{~mm}$, length $10 \mathrm{~mm}$ ) containing an aqueous solution of ${ }^{99 \mathrm{~m}} \mathrm{Tc}$ tin colloid and a contrast medium was used as an external fiducial marker. So that a precise record of both images could be obtained, external fiducial markers were fixed to the common platform for SPECT and CT imaging. The two scans were performed sequentially. Fusion of the SPECT images with the CT images was manually performed by aligning the external fiducial markers of the two images on the workstation, enabling localization of $\mathrm{SN}$ on CT images (Figure 1). An SN was visually identified on the SPECT/CT images by two experienced radiologists before surgery (S.S. and K.K).

\section{Gamma Probe Method}

The radioactivity of the dissected lymph nodes was determined by a handheld gamma probe (Navigator; Auto Suture Japan, Tokyo, Japan), as reported previously. ${ }^{4,5}$ An SN was defined as any node for which the radioactivity count was 10 times that of the background level.

\section{Pathologic Examination}

SNs were examined by intraoperative frozen section analysis using 2- to 3-mm thick sections. The dissected lymph nodes were examined histologically by use of formalin-fixed and paraffinembedded sections with hematoxylin and eosin staining.

\section{Statistical Analysis}

Because the use of a gamma probe to measure radioactivity of dissected lymph nodes is now a standard method for SN identification, the sensitivity of SPECT/CT was examined on the basis of data gathered with the gamma probe, which was calculated as true positive/true positive + false negative. All data were analyzed for statistical significance by the $\chi^{2}$ test. All values in the text and tables are given as mean \pm standard deviation. 

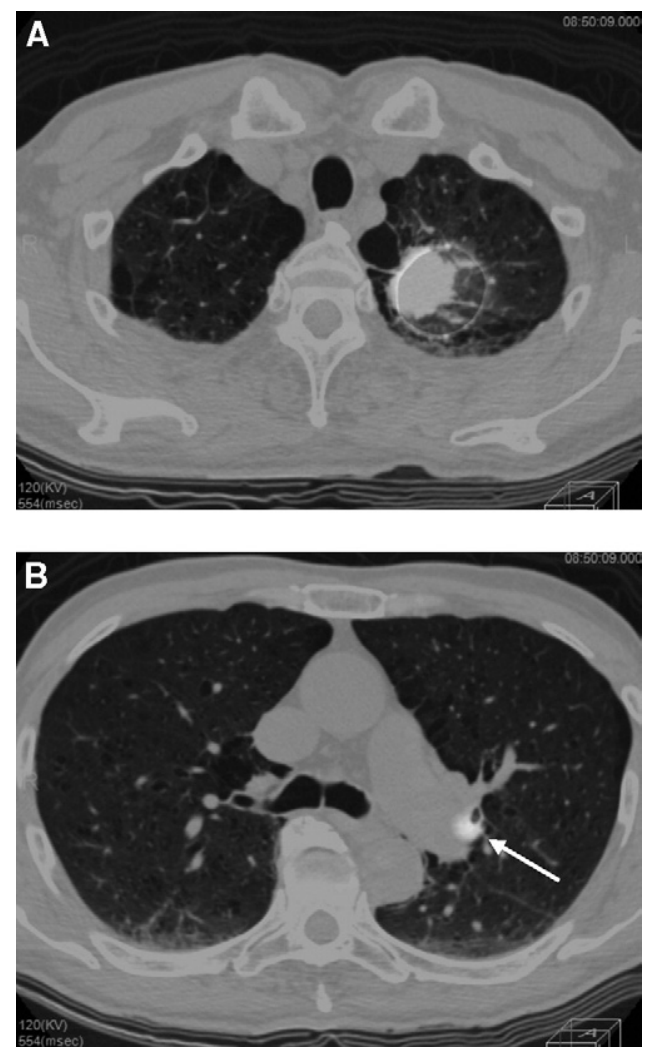

Figure 1. Fused SPECT/CT images in lung cancer of the left upper Iobe. A, Primary tumor. B, Radiolabeled lymph node (segmental nodal station) can be detected (arrow).

\section{Results}

From April 2005 to September 2006, 79 patients with clinical stage Ia peripheral NSCLC underwent surgery at the Department of Thoracic Surgery of Kumamoto University Hospital. Of these, 16 patients could not be enrolled in this study because of the following reasons: (1) Preoperative histologic diagnosis was not obtained in 5 patients; (2) SPECT/CT could not be used because of the other examinations in 10 patients; and (3) one patient refused to participate in the study. As a result, 63 consecutive patients were enrolled in this study. The gamma probe identified SNs in $49(78 \%)$ of the 63 patients, whose pathologic $\mathrm{N}$ stages were N0 in 44, N1 in 2, and N2 in 3 (Table 1). SPECT/CT could identify $\mathrm{SNs}$ in $39(62 \%)$ patients, whose pathologic $\mathrm{N}$ stages were N0 in 34, N1 in 2, and N2 in 3 (Table 2). The SN identification rate by SPECT/CT imaging was lower than that achieved by the gamma probe with marginal significance $(P=.052)$. The mean number of SNs identified by the gamma probe in the 48 patients was $1.6 \pm 0.8$ (range: $1-4)$; the value obtained by SPECT/CT in the 38 patients was $1.5 \pm 0.6$ (range: $1-3$ ). However, there was no significant difference between the two methods in this respect.
TABLE 1. Patient characteristics of SN identification by gamma probe

\begin{tabular}{|c|c|c|}
\hline & \multicolumn{2}{|c|}{$\begin{array}{c}\text { Sentinel nodes by gamma } \\
\text { probe }\end{array}$} \\
\hline & Identified & Not identified \\
\hline \multicolumn{3}{|l|}{ Age (y) } \\
\hline Mean $\pm S D$ & $68 \pm 7$ & $74 \pm 8^{*}$ \\
\hline Range & $53-81$ & $65-82$ \\
\hline \multicolumn{3}{|l|}{ Sex (No.) } \\
\hline Male & 25 & 10 \\
\hline Female & 24 & 4 \\
\hline Mean tumor size (mm) & $19 \pm 7$ & $24 \pm 8 \dagger$ \\
\hline \multicolumn{3}{|l|}{ Tumor location (No.) } \\
\hline Right upper lobe & 13 & 3 \\
\hline Right middle lobe & 2 & 1 \\
\hline Right lower lobe & 8 & 3 \\
\hline Left upper lobe & 17 & 5 \\
\hline Left lower lobe & 9 & 2 \\
\hline \multicolumn{3}{|l|}{ Histologic type (No.) } \\
\hline Adenocarcinoma & 44 & 8 \\
\hline Squamous cell carcinoma & 3 & 6 \\
\hline Adenosquamous carcinoma & 1 & 0 \\
\hline Small cell carcinoma & 1 & 0 \\
\hline \multicolumn{3}{|l|}{ Operative procedure (No.) } \\
\hline Lobectomy & 7 & 4 \\
\hline Segmentectomy & 42 & 10 \\
\hline \multicolumn{3}{|l|}{ p-TNM (No.) } \\
\hline T1 NO MO & 43 & 13 \\
\hline T2 NO MO & 1 & 1 \\
\hline T1 N1 Mo & 2 & 0 \\
\hline T1 N2 M0 & 3 & 0 \\
\hline Total & 49 & 14 \\
\hline
\end{tabular}

$S N$, Sentinel node. ${ }^{*} P=.01 ; \dagger P=.024$.

Between the 49 patients with identifiable SNs and the 14 without by gamma probe, the mean age was younger and the mean tumor size was smaller in the former than in the latter, with significance $(P=.01$ and .024 , respectively). However, there were no significant differences of other variables between patients with identifiable SNs and those without when both the gamma probe and SPECT/CT were used. Tumors in 2 patients were pathologically classified as T2: one tumor was involved over the pleura and the other one was larger than $3 \mathrm{~cm}$ in the permanent section. Although 2 patients needed tube drainage because of pneumothorax after the injection of the isotope, there were no other complications.

Table 3 shows the correlation between SPECT/CT imaging and the gamma probe method for $\mathrm{SN}$ identification at each nodal station of the hilum and mediastinum in the 49 patients whose SNs were identified by gamma probe. In the lymph node stations at the hilum, the gamma probe and SPECT/CT corresponded with each other in 46 (94\%) patients at nodal station No. 10, $46(94 \%)$ at No. 11, $42(86 \%)$ 
at No. 12 , and $39(80 \%)$ at No. 13. In the mediastinum of the right lung, the gamma probe and SPECT/CT corresponded with each other in $21(91 \%)$ patients at nodal station No. 3, in $22(96 \%)$ at No. 4 , and in $22(91 \%)$ at No. 7 . In the mediastinum of the left lung, the gamma probe and SPECT/CT corresponded with each other in $26(100 \%)$ patients at nodal station No. 4 , in $22(85 \%)$ at No. 5 , and in $22(85 \%)$ at No. 7. SNs were not identified at the other mediastinal nodal stations, that is, Nos. 1, 2, 8, and 9, using both methods.

The sensitivity of SPECT/CT based on Table 3 was 0.82 at nodal station No. 13, 0.74 at No. 12, 0.63 at No. 11, 0.40 at No. 10, and 0.31 at the mediastinal nodal stations (Figure 2). The sensitivity of SPECT/CT decreased numerically from nodal station No. 13 to No. 10 and was the lowest in the mediastinal lymph nodes. The sensitivity of SPECT/CT in the mediastinal lymph nodes was significantly lower than those at nodal station No. 13 and No. $12(P<.001$ and $P=.012$, respectively). The specificity of SPECT/CT based on Table 3 was 0.76 at No. 13, 0.93 at N0. 12, 1.0 at N0. 11, 1.0 at No. 10, and 0.99 at the mediastinum.

TABLE 2. Patient characteristics of SN identification by SPECT/CT

\begin{tabular}{|c|c|c|}
\hline & \multicolumn{2}{|c|}{ SNs by SPECT/CT } \\
\hline & Identified & Not identified \\
\hline \multicolumn{3}{|l|}{ Age (y) } \\
\hline Mean $\pm S D$ & $68 \pm 6$ & $69 \pm 7$ \\
\hline Range & $54-81$ & $53-82$ \\
\hline \multicolumn{3}{|l|}{ Sex (No.) } \\
\hline Male & 20 & 15 \\
\hline Female & 19 & 9 \\
\hline Mean tumor size (mm) & $19 \pm 7$ & $20 \pm 7$ \\
\hline \multicolumn{3}{|l|}{ Tumor location (No.) } \\
\hline Right upper lobe & 11 & 5 \\
\hline Right middle lobe & 0 & 3 \\
\hline Right lower lobe & 7 & 4 \\
\hline Left upper lobe & 15 & 7 \\
\hline Left lower lobe & 6 & 5 \\
\hline \multicolumn{3}{|l|}{ Histologic type (No.) } \\
\hline Adenocarcinoma & 34 & 18 \\
\hline Squamous cell carcinoma & 4 & 5 \\
\hline Adenosquamous carcinoma & 0 & 1 \\
\hline Small cell carcinoma & 1 & 0 \\
\hline \multicolumn{3}{|l|}{ Operative procedure (No.) } \\
\hline Lobectomy & 5 & 6 \\
\hline Segmentectomy & 34 & 18 \\
\hline \multicolumn{3}{|l|}{ pTNM (No.) } \\
\hline T1 No Mo & 33 & 23 \\
\hline T2 No Mo & 1 & 1 \\
\hline T1 N1 M0 & 2 & 0 \\
\hline T1 N2 M0 & 3 & 0 \\
\hline Total & 39 & 24 \\
\hline
\end{tabular}

$S N$, Sentinel node; SPECT/CT, single photon emission computed tomography.
TABLE 3. Correlation between SPECT/CT and gamma probe for SN identification

\begin{tabular}{|c|c|c|c|c|c|}
\hline \multirow[b]{3}{*}{ Station } & \multicolumn{4}{|c|}{ Patient number with SN identified by } & \multirow[b]{3}{*}{ Total } \\
\hline & \multicolumn{2}{|c|}{ Gamma probe $(+)$} & \multicolumn{2}{|c|}{ Gamma probe $(-)$} & \\
\hline & $\begin{array}{c}\text { SPECT } \\
(+) \\
\text { True } \\
\text { positive }\end{array}$ & $\begin{array}{c}\text { SPECT } \\
(-) \\
\text { False } \\
\text { negative }\end{array}$ & $\begin{array}{c}\text { SPECT } \\
(+) \\
\text { False } \\
\text { positive }\end{array}$ & $\begin{array}{c}\text { SPECT } \\
(-) \\
\text { True } \\
\text { negative }\end{array}$ & \\
\hline \multicolumn{6}{|l|}{ Hilum } \\
\hline 10 & 2 & 3 & 0 & 44 & 49 \\
\hline 11 & 5 & 3 & 0 & 41 & 49 \\
\hline 12 & 14 & 5 & 2 & 28 & 49 \\
\hline 13 & 23 & 5 & 5 & 16 & 49 \\
\hline \multicolumn{6}{|c|}{ Mediastinum } \\
\hline \multicolumn{6}{|c|}{ Right } \\
\hline 3 & 1 & 2 & 0 & 20 & 23 \\
\hline 4 & 1 & 1 & 0 & 21 & 23 \\
\hline 7 & 0 & 1 & 0 & 22 & 23 \\
\hline \multicolumn{6}{|l|}{ Left } \\
\hline 4 & 1 & 0 & 0 & 25 & 26 \\
\hline 5 & 2 & 3 & 1 & 20 & 26 \\
\hline 7 & 0 & 4 & 0 & 22 & 26 \\
\hline
\end{tabular}

$S N$, Sentinel node; SPECT/CT, single photon emission computed tomography. +, Sentinel node is identified; - , sentinel node is not identified.

Pathologic examination showed lymph node metastases in 5 patients, that is, N1 in 2 patients and N2 in 3 (Table 4). Frozen section of the SNs identified by both SPECT/CT and the gamma probe could show metastases in all 5 patients.

\section{Discussion}

The present study demonstrated that SPECT/CT was inferior to the gamma probe method for $\mathrm{SN}$ identification in the mediastinal lymph nodes. This discrepancy could be caused by the following: (1) the ability to measure radioactivity with SPECT/CT images is inferior to that of direct mea-

\section{Sensitivity}

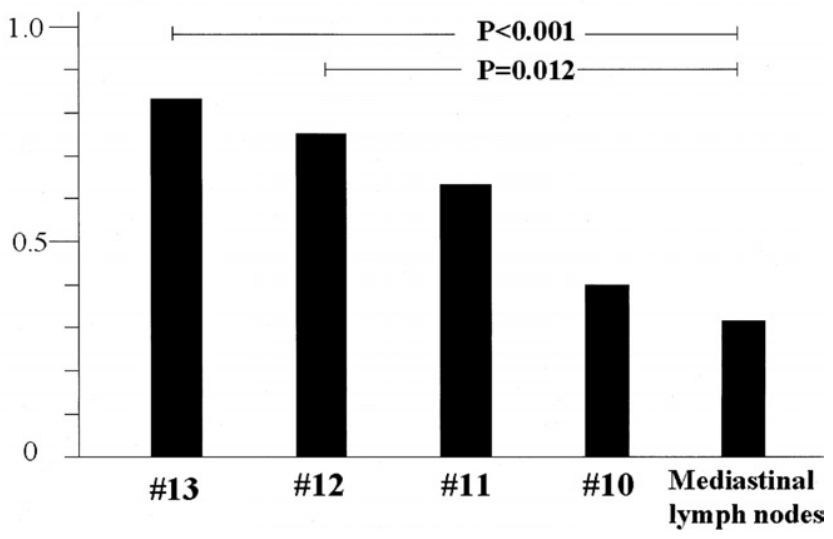

Figure 2. Sensitivity of SPECT/CT at each lymph node station. 
TABLE 4. SNs identified by SPECT/CT and gamma probe in patients with N1 or N2 disease

\begin{tabular}{|c|c|c|c|c|c|c|c|}
\hline \multirow[b]{2}{*}{ No. } & \multirow[b]{2}{*}{ Age/sex } & \multirow[b]{2}{*}{ Tumor location } & \multirow[b]{2}{*}{ Histology } & \multirow[b]{2}{*}{ Metastatic node } & \multicolumn{2}{|c|}{ SN } & \multirow[b]{2}{*}{ pTNM } \\
\hline & & & & & SPECT/CT & Gamma probe & \\
\hline 1 & $60 / \mathrm{M}$ & RLL & $\mathrm{Ad}$ & No. 13 & No. 13 & No. 13 & T1 N1 Mo \\
\hline 2 & $72 / \mathrm{M}$ & RLL & $\mathrm{Ad}$ & No. 11 & No. 11 & No. 11 & T1 N1 Mo \\
\hline 3 & $80 / \mathrm{M}$ & LUL & $\mathrm{Ad}$ & No. 5 & No. 5 & No. 5 & T1 N2 Mo \\
\hline 4 & $59 / \mathrm{M}$ & LUL & $\mathrm{Ad}$ & Nos. $5,12,13$ & Nos. 12,13 & Nos. 5, 12 & T1 N2 M0 \\
\hline 5 & $54 / F$ & LLL & $\mathrm{Ad}$ & Nos. 7, 11, 12 & Nos. 12,13 & No. 12 & T1 N2 Mo \\
\hline
\end{tabular}

$S P E C T / C T$, Single photon emission computed tomography/computed tomography; RLL, right lower lobe; LUL, left upper lobe; $L L L$, left lower lobe; $A d$, adenocarcinoma.

surement by a gamma probe and (2) the radioactivity of mediastinal SNs is usually lower than that of hilar SNs, because the former is further away from the primary tumor. Therefore, we conclude that SPECT/CT cannot easily identify SNs in the mediastinum. However, SPECT/CT could identify SNs at nodal station No. 12 and No. 13 with a sensitivity of 0.82 and 0.74 , respectively. This may be because SNs at nodal station No. 12 and No. 13 are close to the primary tumor, which makes their radioactivity high enough for detection by SPECT/CT. In fact, in 5 patients with $\mathrm{N} 1$ or N2 disease, SPECT/CT imaged metastatic SNs in the hilum before the operation.

$\mathrm{We}^{4}$ previously evaluated $\mathrm{SN}$ identification by using a gamma probe in 104 patients with clinical stage I NSCLC and concluded that although the gamma probe could identify SNs in the mediastinum before lymph node dissection (in vivo SN identification), it could not in the hilum owing to high radioactivity from primary tumors. Because the present study showed the usefulness of SPECT/CT for the in vivo $\mathrm{SN}$ identification in the hilum, we believe that the combination of SPECT/CT and the gamma probe could be useful for in vivo SN identification in both the hilum and the mediastinum.

Recently, it has been reported that segmentectomy could be an alternative to lobectomy for pathologic T1 N0 M0 NSCLC. ${ }^{16,18,19}$ So that the final indication of segmentectomy can be determined, intraoperative frozen sections must be examined for all of the hilar and lobe-specific mediastinal lymph nodes to confirm the intraoperative $\mathrm{N}$ stage to be N0. ${ }^{18,19}$ We consider that the application of SPECT/CT could be used for determining the final indication of segmentectomy as follows: (1) SNs identified in the hilum by SPECT/CT and those identified in the mediastinum by gamma probe are submitted for frozen sections; (2) when frozen sections of SNs show metastases, segmentectomy is converted to lobectomy. Even after segmentectomy, in vivo $\mathrm{SN}$ identification by gamma probe is usually difficult for the hilum owing to high radioactivity in the remaining segments. Therefore, if SPECT/CT is not used, all lymph nodes in the hilum have to be dissected during segmentectomy for SN identification by gamma probe, which is hard as well as time-consuming. On the other hand, for lobectomy, SN identification by SPECT/CT would not be necessary because lymph nodes at the hilum are routinely removed during lobectomy and can be examined for SN identification by gamma probe.

The sensitivities of SN identification at nodal station No. 10 and No. 11 by SPECT/CT were still low. Because station No. 10 is close to the mediastinum, the gamma probe can identify SNs at this station after resection of the primary tumor, as there will no longer be any interference of radioactivity from the primary tumor. Nodal station No. 11 is usually easy to excise even during segmentectomy, enabling $\mathrm{SN}$ identification by gamma probe.

Several tracers have been used for SN identification, such as ${ }^{99 \mathrm{~m}} \mathrm{Tc}$ tin colloid, ${ }^{99 \mathrm{~m}} \mathrm{Tc}$ sulfur colloid, and ${ }^{99 \mathrm{~m}} \mathrm{Tc}$ phytate. Of these, ${ }^{99 \mathrm{~m}} \mathrm{Tc}$ tin colloid has the largest particles, that is, about $1000 \mathrm{~nm}$ in diameter. The reason that we have used ${ }^{99 \mathrm{~m}} \mathrm{Tc}$ tin colloid is as follows. Because the particles of tin colloid are large, they take longer to reach SNs than the other tracers with small particles. In lung cancer surgery, unlike operations for cancer in other organs, radioisotope injected frequently leaks into the tracheobronchus, which makes in vivo $\mathrm{SN}$ identification unreliable immediately after the injection. Because ${ }^{99 \mathrm{~m}} \mathrm{Tc}$ tin colloid has to be injected a few hours before the operation to reach SNs, the material that leaked into the tracheobronchus is already washed out at surgery, resulting in more reliable in vivo SN identification than the other tracers with small particles. ${ }^{4}$ $\mathrm{We}^{4}$ previously confirmed that the radioactivity of ${ }^{99 \mathrm{~m}} \mathrm{Tc}$ tin colloid in SNs was stable from 9 to 24 hours after the injection. On the other hand, ${ }^{99 \mathrm{~m}} \mathrm{Tc}$ sulfur colloid can reach SNs rapidly because of their small particles, approximately $40 \mathrm{~nm}$ in diameter, but could pass through the true SNs and flow further up the chain of nodes, resulting in false negative results. Therefore, ${ }^{99 \mathrm{~m}} \mathrm{Tc}$ sulfur colloid has to be injected immediately before surgery, which would make the in vivo SN identification difficult because of material leaking into the tracheobronchus. In fact, the previous reports using ${ }^{99 \mathrm{~m}} \mathrm{Tc}$ sulfur colloid identified SNs in the dissected lymph nodes but not with in vivo identification. ${ }^{6,7}$ 
In conclusion, SPECT/CT can be used to identify SNs in the hilum before surgery, especially at nodal station No. 12 and No. 13, but not in the mediastinum. Because the gamma probe method can identify SN before lymph node dissection in the mediastinum but not in the hilum, a combination of SPECT/CT and the gamma probe could be used to identify SNs before lymph node dissection in both the hilum and the mediastinum. This will enable SN navigation surgery in patients with clinical stage Ia NSCLC, especially for segmentectomy.

\section{References}

1. Tafra L, Lannin DR, Swanson MS, Eyk JJV, Verbanac KM, Chua AN, et al. Multicenter trial of sentinel node biopsy for breast cancer using both technetium sulfur colloid and isosulfan blue dye. Ann Surg. 2001; 233:51-9.

2. Morton DL, Thompson JF, Essner R, Elashoff R, Stern SL, Nieweg $\mathrm{OE}$, et al. Validation of the accuracy of intraoperative lymphatic mapping and sentinel lymphadenectomy for early-stage melanoma. Ann Surg. 1999;230:453-65.

3. Kitagawa Y, Fujii H, Mukai M, Kubota T, Ando N, Watanage M, et al. The role of the sentinel lymph node in gastrointestinal cancer. Surg Clin North Am. 2000;80:1799-809.

4. Nomori H, Watanabe K, Ohtsuka T, Naruke T, Suemasu K. In vivo identification of sentinel nodes for clinical stage I non-small cell lung cancer for abbreviation of mediastinal lymph node dissection. Lung Cancer. 2004;46:49-55.

5. Nomori H, Horio H, Naruke T, Orikasa H, Yamazaki K, Suemasu K. Use of technetium-99m tin colloid for sentinel lymph node identification in non-small cell lung cancer. J Thorac Cardiovasc Surg. 2002; 124:486-92.

6. Liptay MJ, Masters GA, Winchester DJ, Edelman BL, Carrido BJ, Hirshctritt TR, et al. Intraoperative radioisotope sentinel lymph node mapping in non-small cell lung cancer. Ann Thorac Surg. 2000;70: 384-90.

7. Liptay MJ, Grondin SC, Fry WA, Pozdol C, Carson D, Knop C, et al. Intraoperative sentinel lymph node mapping in non-small cell lung cancer improves detection of micrometastases. J Clin Oncol. 2002;20: 1984-8.
8. Schmidt FE, Woltering EA, Webb WR, Garcia OM, Cohen JE, Rozans MH. Sentinel nodal assessment in patients with carcinoma of the lung. Ann Thorac Surg. 2002;74:870-4.

9. Melfi FM, Chella A, Menconi GF, Givigliano F, Boni G, Mariani G, et al. Intraoperative radioguided sentinel lymph node biopsy in nonsmall cell lung cancer. Eur J Cardiothorac Surg. 2003;23:214-20.

10. Sugi K, Kaneda Y, Sudoh M, Sakano H, Hamano K. Effect of radioisotope sentinel node mapping in patients with cT1 N0 M0 lung cancer. J Thorac Cardiovasc Surg. 2003;126:568-73.

11. Carlson GW, Murray DR, Greenlee R, Alazraki N, Fry-Spray C, Poole $\mathrm{R}$, et al. Management of malignant melanoma of the head and neck using dynamic lymphoscintigraphy and gamma-probe-guided sentinel lymph node biopsy. Arch Otolaryngol Head Neck Surg. 2000;126: 433-7.

12. de Wilt HW, Thompson JF, Uren RF, Ka VS, Scolyer RA, McCarthy $\mathrm{WH}$, et al. Correlation between preoperative lymphoscintigraphy and metastatic nodal disease sites in 362 patients with cutaneous melanoma of the head and neck. Ann Surg. 2004;239:544-52.

13. Albertini JJ, Cruse CW, Rapaport D, Wells K, Ross M, DeConti R, et al. Intraoperative radio-lymphoscintigraphy improves sentinel lymph node identification for patients with melanoma. Ann Surg. 1996;223: 217-24.

14. Ishihara T, Kaguchi A, Matsushita S, Shiraishi S, Tomiguchi S, Yamashita $Y$, et al. Management of sentinel lymph nodes in malignant skin tumors using dynamic lymphoscintigraphy and the single-photonemission computed tomography/computed tomography combined system. Int J Clin Oncol. 2006;11:214-20.

15. Nomori H, Horio H, Naruke T, Suemasu K. What is the advantage of a thoracoscopic lobectomy over a limited thoracotomy procedure for lung cancer surgery? Ann Thorac Surg. 2001;72:879-84.

16. Nomori H, Ikeda K, Mori T, Kobayashi H, Iwatani K, Kawanaka K, et al. Sentinel node navigation segmentectomy for c-T1 N0 M0 nonsmall cell lung cancer $J$ Thorac Cardiovasc Surg. 2007;133:780-5.

17. Naruke T, Suemasu K, Ishikawa S. Lymph node mapping and curability at various levels of metastasis in resected lung cancer. J Thorac Cardiovasc Surg. 1978;76:832-9.

18. Okada M, Yoshikawa K, Hatta T, Tsubota N. Is segmentectomy with lymph node assessment an alternative to lobectomy for non-small cell lung cancer of $2 \mathrm{~cm}$ or smaller? Ann Thorac Surg. 2001;71:956-61.

19. Yoshikawa K, Tsubota N, Kodama K, Ayabe H, Taki T, Mori T, et al. Prospective study of extended segmentectomy for small lung tumors: the final report. Ann Thorac Surg. 2002;73:1055-9. 